\title{
Enhancing the Operational Resilience of Advanced Reactors with Digital Twins by Recurrent Neural Networks
}

\section{October 2021}

Linyu Lin, Joomyung Lee, Bikash Poudel, Timothy R McJunkin, Nam Dinh, Vivek Agarwal

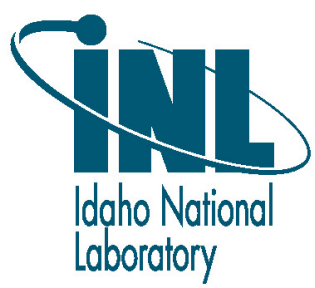




\section{DISCLAIMER}

This information was prepared as an account of work sponsored by an agency of the U.S. Government. Neither the U.S. Government nor any agency thereof, nor any of their employees, makes any warranty, expressed or implied, or assumes any legal liability or responsibility for the accuracy, completeness, or usefulness, of any information, apparatus, product, or process disclosed, or represents that its use would not infringe privately owned rights. References herein to any specific commercial product, process, or service by trade name, trade mark, manufacturer, or otherwise, does not necessarily constitute or imply its endorsement, recommendation, or favoring by the U.S. Government or any agency thereof. The views and opinions of authors expressed herein do not necessarily state or reflect those of the U.S. Government or any agency thereof. 


\section{Enhancing the Operational Resilience of Advanced Reactors with Digital Twins by Recurrent Neural Networks}

Linyu Lin, Joomyung Lee, Bikash Poudel, Timothy R McJunkin, Nam Dinh, Vivek Agarwal

October 2021

Idaho National Laboratory

Idaho Falls, Idaho 83415

http://www.inl.gov

Prepared for the U.S. Department of Energy Under DOE Idaho Operations Office

Contract DE-AC07-05ID14517 


\section{Enhancing the Operational Resilience of Advanced Reactors with Digital Twins by}

\section{Recurrent Neural Networks}

\section{Abstract}

With a lack of reactor operation data during system anomalies, the established emergency operating procedures can be biased in characterizing reactor states and identifying the optimal path of recovery from system anomaly.

In this paper, we suggest digital twin (DT) technology and demonstrate two DT functions for improving operational resilience of nuclear reactors: diagnosis digital twin (DT-D) for improving state awareness and prognosis digital twin (DT-P) for ensuring operational flexibility for minimizing effects on the system due to anomalies.

\section{Potential Impacts}

Enable autonomous control systems of advanced reactors to detect, response to, and mitigate system anomalies for real-time emergency controls:

- State awareness: Reactor states, including safety-significant factors and unobservable states variables, are monitored and reported by DT-D in real time.

- Anticipatory control: Action effects are accurately predicted by DT-P based on the knowledge base and the real-time sensor readings.

- Reconfiguration: System safety, performance, and component reliability can be achieved at preferred levels when selecting optimal control options.

\section{Research Approach}

A DT Development and Assessment Process (DAP) is followed to implement and evaluate DT-D and DT-P:

- Requirements: Accuracy in diagnosing and prognosing reactor states measured by root mean square error (RMSE).

- Knowledge base: Experimental Breeder Reactor-II operating procedures and three simulation databases with different flow anomalies.

- Digital twin: DT-D and DT-P by recurrent neural networks (RNNs) based on a training database.

Digital twin assessment: Separate assessment with testing databases, including anomalies of different magnitudes, noises, and biased sensor signals.
Linyu Lin, Bikash Poudel, Timothy McJunkin, Vivek Agarwal (Idaho National Laboratory) Joomyung Lee, Nam Dinh (North Carolina State University)

\section{Result}

Both DT-D and DT-P are modeled by recurrent neural networks, while one of three different databases (Transient $B$ ) is selected as the training data. Transient $C$ is more different from Transient $B$ than Transient $A$.

- The accuracy of DTs indicate the degree of State Variable state awareness and operational flexibility.

- DT-D by RNN shows acceptable accuracy in predicting different testing databases and faulty sensor signals.

- DT-P shows acceptable accuracy in predicting state variables and rewards of training only.

\begin{tabular}{|c|c|c|c|c|}
\hline State Variable & Testing Data & $\begin{array}{l}\text { RMSE in } \\
\text { Predicting th } \\
\text { Transients }\end{array}$ & & $\begin{array}{l}\text { RMSE in } \\
\text { Predicting the } \\
\text { Rewards }\end{array}$ \\
\hline \multirow{8}{*}{$\begin{array}{c}\text { DT-D } \\
\text { peak fuel } \\
\text { centerline } \\
\text { temperature } \\
\mathrm{T}_{\mathrm{PFCL}}\left({ }^{\circ} \mathrm{C}\right)\end{array}$} & Transient A & 1.67 & Q & - \\
\hline & Transient B (training) & 0.83 & Q & 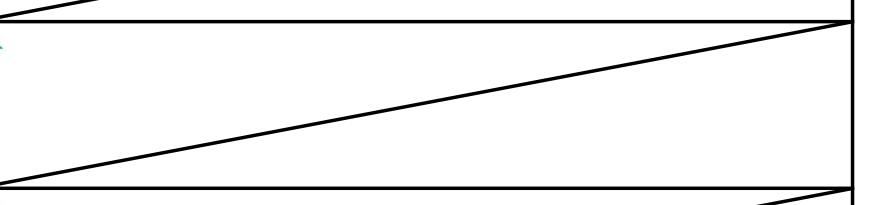 \\
\hline & Transient C & 2.38 & s) & - \\
\hline & 1 sensor no signal & 2.33 & S & 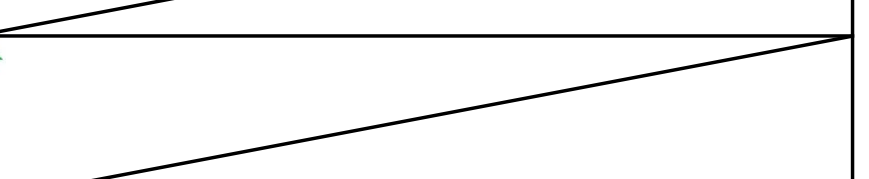 \\
\hline & 2 sensor no signal & 2.92 & Q & 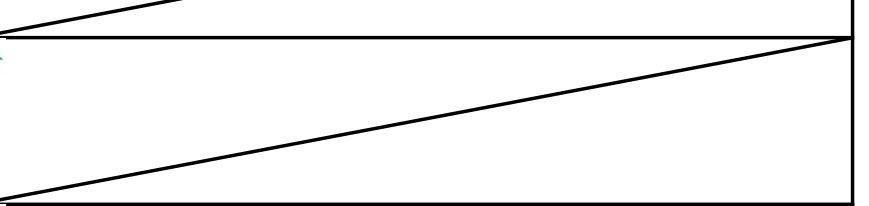 \\
\hline & 1 sensor drift (1\%) & 0.18 & Q & \\
\hline & 2 sensor drift (1\%) & 0.11 & 8 & 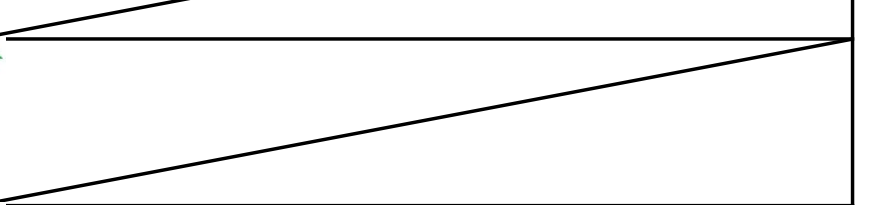 \\
\hline & Random drift (1\%) & 3.19 & 8 & - \\
\hline \multirow{3}{*}{$\begin{array}{c}\text { DT-P } \\
T_{\mathrm{PFC}}\left({ }^{\circ} \mathrm{C}\right)\end{array}$} & Transient A & 4.43 & $\sigma_{1}^{-}$ & $88.59 \&$ \\
\hline & Transient B (training) & 1.70 & 8 & 44.68 \& \\
\hline & Transient C & 4.27 & $\theta_{1}^{-}$ & 107.02 \\
\hline \multirow{3}{*}{$\begin{array}{c}\text { DT-P } \\
\text { core power } \\
\text { rates (MW) }\end{array}$} & Transient A & 1.44 & 8 & 216.92 \\
\hline & Transient B (training) & 0.69 & $\sigma_{1}^{-}$ & 88.30 \& \\
\hline & Transient C & 1.31 & $\theta_{1}$ & 204.49 \\
\hline
\end{tabular}

Summary and Path Forward

- An accurate DT-D improves the visibility of plant states. An accurate DT-P enhances the awareness of action consequences and helps ensure operational flexibility to select optimal options based on preferences from all stakeholders.

- Deploy DTs onto autonomous control system of modular and microreactors.

- Investigate different modeling approaches and improve the DT DAP.

This work is supported through the INL Laboratory Directed Research\& Development (LDRD) Program under DOE Idaho Operations Office Contract DE-AC07-05ID14517 and by Advanced Research Projects Agency-Energy MEITNER program under Contract No. DE-AR0000976. 